\title{
Attitudes towards sexual offenders: What do we know, and why are they important?
}

Article in Aggression and Violent Behavior - January 2017

DOI: 10.1016/j.avb.2017.01.011

CITATIONS

0

3 authors:

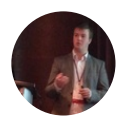

Craig Harper

Nottingham Trent University

15 PUBLICATIONS 24 CITATIONS

SEE PROFILE

Ross Bartels

University of Lincoln

17 PUBLICATIONS 36 CITATIONS

SEE PROFILE
READS

12

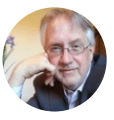

Todd E Hogue

University of Lincoln

45 PUBLICATIONS 708 CITATIONS

SEE PROFILE

Some of the authors of this publication are also working on these related projects:

Project Examining the horseshoe-nature of political orientation and action View project

Exploring The Effectiveness Of Treatment Programmes For Sexual offenders with Autism Spectrum

Project

Disorder (ASD) View project

All content following this page was uploaded by Craig Harper on 20 January 2017. 


\section{Accepted Manuscript}

Attitudes towards sexual offenders: What do we know, and why are they important?

Craig A. Harper, Todd E. Hogue, Ross M. Bartels

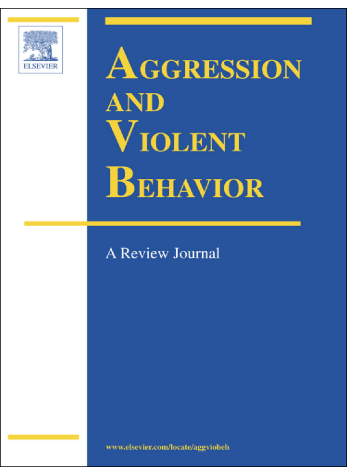

PII:

S1359-1789(17)30026-5

DOI: doi: 10.1016/j.avb.2017.01.011

Reference: AVB 1082

To appear in: Aggression and Violent Behavior

Received date: 23 January 2016

Revised date: 11 May 2016

Accepted date: 18 January 2017

Please cite this article as: Craig A. Harper, Todd E. Hogue, Ross M. Bartels, Attitudes towards sexual offenders: What do we know, and why are they important?. The address for the corresponding author was captured as affiliation for all authors. Please check if appropriate. Avb(2017), doi: 10.1016/j.avb.2017.01.011

This is a PDF file of an unedited manuscript that has been accepted for publication. As a service to our customers we are providing this early version of the manuscript. The manuscript will undergo copyediting, typesetting, and review of the resulting proof before it is published in its final form. Please note that during the production process errors may be discovered which could affect the content, and all legal disclaimers that apply to the journal pertain. 
Running head: Attitudes towards sexual offenders

Attitudes towards sexual offenders: What do we know, and why are they important?

\author{
Craig A. Harper* \\ Nottingham Trent University (UK) \\ Todd E. Hogue and Ross M. Bartels \\ University of Lincoln (UK)
}

Author Note

Craig Harper - Lecturer in Human Psychology, Nottingham Trent University, UK

Todd Hogue - Professor of Forensic Psychology, University of Lincoln, UK

Ross Bartels - Senior Lecturer in Forensic Psychology, University of Lincoln, UK

* Correspondence concerning this article should be addressed to Craig Harper, Department of Psychology, Nottingham Trent University, Nottingham, NG1 4BU, UK

Email: craigaharper19@gmail.com 


\begin{abstract}
Over the past two decades, a large body of research on attitudes towards sexual offenders has been conducted across a number of different contexts. However, there has been less discussion of their implications. Clinically, attitudes may be related to therapeutic climates and treatment outcomes and risk judgments, while in the social context, the views of the public about sexual offenders may play a key role in the reintegration of these offenders, and the political responses associated with sexual offending. Sexual crime is advocated as a public health issue, with attitudes towards the perpetrators of such offenses being of critical importance when trying to create a social environment within which to successfully reduce rates of sexual offending. In this article, the research evidence currently available in this area is reviewed. An analysis of the conceptualization and measurement of attitudes towards sexual offenders is provided, before the existing literature on the factors underlying such attitudes is explored. Following this, the malleability of attitudes towards sexual offenders is examined. The review concludes with some suggestions for future theoretical, empirical, and practical advancements in this important area.
\end{abstract}

Keywords: attitudes, sexual offenders, treatment, desistance, reintegration, sexual crime, review 


\section{Attitudes towards sexual offenders: What do we know, and why are they important?}

\section{Introduction}

The study of attitudes towards sexual offenders is a popular topic for empirical inquiry in the study of social views about the criminal justice system. Theoretical accounts from criminological and social studies indicate that attitudes towards sexual offenders could have profound implications for clinical and social decision-making (LeBel, Burnett, Maruna, \& Bushway, 2008; Willis, Levenson, \& Ward, 2010). For example, societal negativity about sexual offenders has been linked to a range of disadvantages for this group upon their reentering society after serving criminal sentences. These include difficulties in accessing stable housing arrangements (Clark, 2007), and organized attempts to drive them out of communities (e.g., Kitzinger, 2008). Despite these potential implications, Brown (2009) suggested that there is a dearth of knowledge about the concepts and processes that underpin these attitudes. This lack of knowledge leads us to risk attempting to influence changes in attitudes towards sexual offenders using a 'one-size-fits-all' approach. This method of influencing attitude change may fail to reap the intended improvements in attitudes if some members of society hold particular beliefs or attitudinal stances about this group. As such, it is important to take stock of what we currently know about attitudes towards sexual offenders in order to develop new research streams. This exercise has the potential to re-focus this field of study, and assist scholars in meeting the longer-term goals of their research programs (i.e., theory development, attitude improvement, effective policymaking, and reduced offending rates).

Brown's (2009) chapter on public opinions about sexual offenders represents one related review of this area. However, this chapter's focus was on public opinion around sentencing policy, and as such did not examine different approaches to measuring attitudes, 
factors influencing attitudes, or the potential utility of considering attitudes in relation to clinical practice and reintegration processes. Similarly, Willis et al. (2010) presented a conceptual paper that sought to highlight the relevance of attitudes towards sexual offenders when considering desistance from sexual offending. However, covering the psychological factors underpinning such attitudes was not within the scope of their article. As such, the present article represents an overdue summary of what we currently know about attitudes towards sexual offenders. In light of this, we provide a comprehensive review of the international literature on attitudes towards sexual offenders, addressing five key domains. First, we set the scene by discussing the important conceptual distinction between attitudes and perceptions, before moving on to an examination of the methodological issues surrounding the measurement of attitudes in this area of research. Second, from surveying the literature, we consolidate what is currently known about the factors that underpin attitudes towards sexual offenders. Third, we address the malleability of these attitudes, with a critical discussion of the studies that have sought to change them. Fourth, we examine the importance of attitudes towards sexual offenders in terms of their implications within both clinical and social contexts. Finally, opportunities to progress this field of study are brought together, along with several suggestions for future avenues of research. These suggestions for future research are also incorporated within the appropriate sections of our review of the literature.

\subsection{Discriminating 'attitudes' from 'perceptions'}

An attitude is defined as "psychological tendency that is expressed by evaluating a particularly entity with some degree of favour or unfavour” (Eagly \& Chaiken, 1993, p. 1). They are conceptualized as being comprised of three distinct components (Breckler, 1984): (1) cognition - which is related to the types of beliefs (i.e., stereotypes) that a person holds about a particular concept or entity; (2) affect - which refers to the visceral emotional 
response that people have towards a particular topic or entity; and (3) behavior - referring to the ways in which people act within the physical world with reference to the concept or entity under consideration. These three components of attitudes are all important, and it has been suggested that many researchers do not comprehensively consider all of these components when studying attitudes about sexual offenders (Hogue, 2015).

What many studies do examine, however, are 'perceptions' about sexual offenders. Conceptually, perceptions are more akin to stereotypical views and, thus, are primarily comprised of knowledge-based attributions about a topic or entity (Jussim, 2012). Thus, unlike attitudes, they do not represent evaluations of a topic or entity. In this sense, only examining perceptions is a much narrower approach than examining attitudes. By examining attitudes (in a manner consistent with Breckler's (1984) conceptualization), it is possible to look deeper at the processes underpinning perceptions (through evaluations of affective responses), and further to investigate the potential implications of perceptions (through evaluations of behavioral responses). Throughout this review, our primary focus in on research into attitudes towards sexual offenders.

\section{Measuring attitudes and perceptions about sexual offenders}

In order to accurately discuss the attitudes towards sexual offenders literature, it is first appropriate to outline the methods that are currently used by researchers in order to measure these constructs. Thus, in this section we identify, describe, and compare some of the key methods used by scholars in this area. We believe that an examination of these approaches to attitude measurement is both relevant and pertinent to the comprehensiveness of the review that we offer in this article. No review to date has systematically examined these measures together, and so this exercise offers a useful starting point for researchers seeking to design studies in this area of empirical inquiry. 


\subsection{The Attitudes to Sexual Offenders (ATS) scale}

The Attitudes to Sexual Offenders scale (ATS; Hogue; 1993) was developed as a 36item self-report measure, designed to capture respondents' affective and evaluative judgments about sexual offenders. The ATS was adapted from the Attitudes to Prisoners scale (ATP; Melvin, Gramling, \& Gardner, 1985), with Hogue (1993) modifying the ATP by substituting the word 'prisoners' for the phrase 'sex offenders'.

ATS items are framed as attitudinal statements (e.g., "Sex offenders are no better or worse than other people"), with respondents rating their level of agreement with each statement. Each item is rated using a five-point Likert scale (ranging from 0 'Strongly Disagree' to 4 'Strongly Agree'; 19 of which are reverse scored). This leaves a potential scoring range of $0-144$, with higher scores indicating positive attitudes towards sexual offenders. The ATS has repeatedly been shown to have very good internal consistency ( $\alpha$ 's > 0.85) across a range of different samples (Craig, 2005; Higgins \& Ireland, 2009; Kjelsberg \& Loos, 2008; Kleban \& Jeglic, 2012; Proeve \& Howells, 2006).

Anonymous (in prep) have developed a shortened version of the ATS (the 'ATS-21'). Drawing on data from three large European community samples, this revised scale consists of 21 of the original ATS items, of which 11 are reverse-scored. These items load equally on to three seven-item factors, labeled 'Trust', 'Intent', and 'Social Distance'. The ATS-21 has a potential scoring range of $0-84$, with higher scores indicating positive attitudes towards sexual offenders. The ATS-21 also correlates extremely highly with the original 36-item ATS $(r=.98, p<.001)$, and demonstrates excellent levels of internal consistency $(\alpha=0.94$; Anonymous, in prep).

The ATS (and by extension, the ATS-21) can be said to provide a comprehensive examination of all three components of attitudes. The 'Trust' factor represents affect-based 
judgments about sexual offenders (e.g., "I would like associating with some sex offenders"), the 'Intent' factor examines cognitive (i.e., stereotype-related) evaluations of sexual offenders (e.g., "Sex offenders only think about themselves"; reverse-scored), and the "Social Distance" factor acts as a behavior-related measure of views about sexual offenders (e.g., "If sex offenders do well in prison/hospital, they should be let out on parole").

Despite its status as a measure of stable attitudes (Hogue, 2015), several authors have used the ATS scale as an outcome measure. That is, researchers have manipulated ATS items in order to examine respondents' attitudes towards specific 'types' of sexual offenders. Examples of such work include analyses of attitudes towards female sexual offenders (e.g., Gakhal \& Brown, 2011), and juvenile sexual offenders (e.g., Harper, 2012). Given the conceptually stable nature of attitudes (Hogue, 2015), this approach to ATS research may present problems for researchers trying to understand and interpret the attitudes towards sexual offenders literature as a complete corpus. Fuller information about the differences in these studies are provided in subsequent sections of this review.

\subsection{The Community Attitudes Towards Sex Offenders (CATSO) scale}

The Community Attitudes Towards Sex Offenders scale (CATSO; Church, Wakeman, Miller, Clements, \& Sun, 2008) is an 18-item self-report measure. It was developed as an alternative to other measures that, according to Church et al. (2008), had either: (a) not been adequately validated, or (b) been developed based on measures designed to examine attitudes towards other (i.e., general offender) populations.

Like the ATS, CATSO items are composed as statements about sexual offenders (e.g., "Most sex offenders are unmarried men"). Respondents indicate their level of agreement with each statement using a six-point Likert scale, anchored from 1 'Strongly Disagree' to 6 'Strongly Agree'. Scores for each of the items are summed to provide a composite CATSO 
score that can range from 18-108 (higher scores indicate more negative views about sexual offenders). In a range of studies, the CATSO has demonstrated acceptable levels of internal consistency ( $\alpha=0.74$; Church et al., 2008; Conley, Hill, Church, Stoeckel, \& Allen, 2011; Jones, 2013; Malinen, Willis, \& Johnston, 2014; Shackley, Weiner, Day, \& Willis, 2014; Shelton, Stone, \& Winder, 2013).

Church et al.'s (2008) initial factor analyses of the CATSO data identified an underlying four-factor structure, with these factors being labeled 'Social Isolation', 'Capacity to Change', 'Dangerousness', and 'Deviancy'. Each of these factors (with the exception of Deviancy) demonstrated acceptable levels of internal consistency (all $\alpha$ 's > 0.70). A number of studies have sought to validate the CATSO with new factor analyses (e.g., Conley et al., 2011; Shackley et al., 2014; Shelton et al., 2013; Tewksbury \& Mustaine, 2013). However, none of these studies (with the exception of Tewksbury \& Mustaine, 2013) have reported the same underlying factor structure as Church et al. (2008). Some studies have found the CATSO to be comprised of two factors (e.g., 'Social Isolation' and 'Capacity for Change'; Conley et al., 2011), while others have identified a different four factor structure than that reported in Church et al.'s (2008) original development paper (e.g., 'Social Tendencies', 'Treatment and Punishment', 'Crime Characteristics', and 'Sexual Behavior'; Shackley et al., 2014). Interpreting this latter structure, there is a case to be made that the CATSO actually examines knowledge-based attributions about sexual offenders (and thus is a measure of 'perceptions', rather than 'attitudes'). This lack of structural consistency has led to some authors calling for partial or complete overhauls of the CATSO (Conley et al., 2011; Harper \& Hogue, 2015a; Shackley et al., 2014; Shelton et al., 2013).

With regard to research conducted using the CATSO, this measure has primarily been used in order to examine the attitudes of different demographic or professional groups 
towards sexual offenders (e.g., Shackley et al., 2014; Tewksbury \& Mustaine, 2013). These studies will be discussed in more detail in subsequent sections of this review.

\subsubsection{The Perceptions of Sex Offenders (PSO) scale}

Noting the CATSO's inconsistent factor structure, Harper and Hogue (2015a) published data that sought to reimagine the measure. First, they undertook a face validity analysis of the CATSO items using Breckler's (1984) three component view of attitudes as a theoretical guide. They concluded that the CATSO predominantly measures stereotype-related cognitions and behavioral approaches to managing sexual offenders, but omits affect-based views. This structure means that, in addition to not comprehensively measuring all components of attitudes, the CATSO fails to meet the criteria of an 'attitude' measure when using Eagly and Chaiken's (1993) broader (i.e., evaluations of favor or disfavor) conceptualization of this construct.

In response to this, Harper and Hogue (2015a) removed all poorly-loading CATSO items as recommended by Conley et al. (2011) and Shelton et al. (2013), and added eight new items that were a better conceptual fit with the rest of the scale. This resulted in a 20-item scale. Using a sample of 400 community volunteers, principal components and confirmatory factor analyses of the new scale revealed four underlying factors, which were labeled 'Sentencing and Management', 'Stereotype Endorsement', and 'Risk Perception'. Each of these factors demonstrated good levels of internal consistency (all $\alpha$ 's $>0.80$ ), with the revised scale as a whole - named the Perceptions of Sex Offenders (PSO) scale - having a Cronbach's alpha of 0.92 .

Harper and Hogue (2015a) suggested that the PSO (as a measure of perceptions) and attitudinal measures (e.g., the ATS-21) are not in competition, as has often been conceptualized within the literature (e.g., Church et al., 2008), but are rather complimentary. 
For example, the ATS-21 can be used as a baseline measure of generalized attitudes towards sexual offenders, while the PSO is conceptualized as an outcome measure, against which the effectiveness of attitudinal interventions can be assessed. Due to being a newly-established measure, there have been no published studies (as yet) that use the PSO as a tool for examining people's perceptions of sexual offenders. However, its inclusion in this review is warranted, as the PSO represents a conceptual development in the understanding the tools used for measuring attitudes towards sexual offenders.

\subsection{Non-standardized measures of perceptions of sexual offenders}

In addition to the more established measures described above, a range of authors have used other self-report approaches to examine attitudes and perceptions of sexual offenders. Wnuck, Chapman, and Jeglic (2006) developed the Attitudes towards the Treatment of Sex Offenders scale (ATTSO). This is a 15-item self-report questionnaire with three underlying factors ('Incapacitation', 'Treatment Ineffectiveness', and 'Mandatory Treatment'), and examines the degree to which respondents favor or object to the treatment of sexual offenders, or believe in treatment efficacy. Despite original claims that the ATTSO could be used as a scoping tool for identifying sites for sexual offender treatment facilities, the measure has not been validated or utilized comprehensively enough since its inception, and so few insights can be drawn from it.

A number of studies have developed their own measures for assessing what they refer to as 'attitudes' towards sexual offenders. These studies, however, typically use policy positions as self-report items, and measure the endorsement of these propositions as a proxy for attitudes. Levenson, Brannon, Fortney, and Baker (2007), for example, examined public perceptions of registrations and community notification laws (see also Kernsmith, Craun, \& Foster, 2009). Higher levels of endorsement of these kinds of procedures are taken to be 
indicative of a punitive stance, and as such are interpreted as being indicative of negative attitudes towards sexual offenders. Further, authors such as Brown (1999) have examined attitudes towards the treatment of sexual offenders. In these studies, support for sexual offender treatment is potentially consistent with the view that these individuals can change (which in turn has been associated with more positive attitudes towards sexual offenders; Harper \& Bartels, in press). The findings from these approaches offer interesting insights into politically-relevant responses to sexual crime. However, in terms of construct validity, they are not strictly a direct reflection of one's 'attitude' towards sexual offenders, despite often being labeled as such. We argue that scholars should exercise caution in interpreting sentencing- and risk-related studies within the context of attitudes towards sexual offenders, as these ideas (while clearly related) examine conceptually different issues.

\subsection{Indirect assessment of attitudes towards sexual offenders}

In comparison to self-report measures, there is a growing trend within social psychology to make use of indirect measurement procedures when assessing attitudes (Gawronski \& De Houwer, 2014). Self-report measures (e.g., questionnaires) assess consciously accessible (explicit) attitudes by asking participants to directly respond to individual statements (or propositions; Gawronski \& Bodenhausen, 2006). As such, attitudinal questionnaires can be influenced by situational factors, such as mood or externally-presented stimuli (Visser \& Cooper, 2003), as well as by socially desirable responding, especially if the attitude being measured is of a sensitive nature. In contrast, indirect measures require participants to perform a task (e.g., categorizing specific stimuli as fast as possible), the outcome of which (e.g., response-latencies) can be used to infer an attitudinal stance. For example, the Implicit Association Test (IAT; Greenwald, McGhee, \& Schwartz, 1998) is commonly used as an indirect measure of attitudes. In brief, it compares 
how fast participants categorize stimuli into one paired category (e.g., 'sex offenders-bad') relative to an opposing paired category ('sex offender-good'). In this example, an individual who produced faster response-latencies for the former category would be presumed to hold a stronger association between 'sex offender' and 'bad' in their memory, relative to an association between 'sex offender' and 'good'. As such, it can be inferred that hold a negative attitude towards sexual offenders.

Indirect methods are often used to examine implicit attitudes; that is, immediate evaluative reactions resulting from associative processes, which are typically outside an individual's conscious control or awareness (Gawronski \& Bodenhausen, 2006). However, due to the indirect nature of their procedure, indirect measures also allow for sensitive or socially-contentious attitudes to be more effectively measured without the influence of social desirability. As such, we argue that there may be considerable benefits in using such indirect procedures in the assessment of attitudes towards sexual offenders, given the sociallycontentious nature of the topic.

In the only published study using an indirect assessment of attitudes towards sexual offenders, Malinen et al. (2014) made use of a Single-Target Implicit Association Test (STIAT; Wigboldus, Holland, \& van Knippenberg, 2006). Specifically, their participants were asked to associate words related to 'sexual offenders' (e.g., 'rapist', 'molester') with positive words (e.g., 'happy', 'pleasure') in one block, and with negative words (e.g., 'hate', 'evil') in another block. The differences in average response times were then used to compute an index of implicit attitudes towards sexual offenders (such that faster response times in, for example, the negative block were indicative of a more negative attitude towards sexual offenders).

Malinen et al. (2014) reported a positive a correlation $(r=.41)$ between implicit attitudes and CATSO scores. While this suggests a reliable relationship between outcomes on these different measurement approaches, there is still a substantial amount of variance unaccounted 
for. Malinen et al. (2014) did not fully elaborate on this particular aspect of their results. However, a brief examination of the theoretical literature would suggest that sociallydesirable responding, as well as study-specific demand characteristics in explicit responding, may be relevant and important factors for consideration (Banse \& Imhoff, 2013). It is also possible that the two measures (i.e., the CATSO and the ST-IAT) were tapping distinct, but related, constructs. A fuller description of the content of Malinen et al.'s (2014) study, including a discussion about the effects of experimental manipulations on both explicit (CATSO) and implicit (ST-IAT) attitudes, is provided in subsequent sections of this review.

\subsection{Section summary}

Breckler's (1984) tripartite structure of attitudes (cognition, affect, and behavior) appears to be differentially reflected in existing attitudinal measures about sexual offenders. The revised ATS-21 (Anonymous, in prep) is arguably the most comprehensive measure of all three attitudinal domains, with underlying factors of 'Trust' (an affective attitudinal domain), 'Intent' (a cognitive attitudinal domain), and 'Social Distance' (a behavioral attitudinal domain). In contrast, the much-used CATSO measure has repeatedly been shown to have variable levels of internal consistency, as well as an inconsistent underlying factor structure. Harper and Hogue's (2015a) PSO offers a promising alternative to the CATSO, which they argue is conceptually different to the ATS-21. Thus, it is argued that the ATS-21 and PSO should be used in tandem in order to examine the influence of pre-existing attitudes on experimental manipulations (see also Anonymous, in prep).

Indirect measurement procedures, such as those used by Malinen et al. (2014), are a scarcity within this research area. This should be addressed in future research as they can offer useful insights into the mental associations that people hold about sexual offenders, and 
can be used to investigate whether explicit (self-report) measures are subject to politicallyand/or socially-motivated responding (Banse \& Imhoff, 2013).

\section{Factors underpinning attitudes and perceptions about sexual offenders}

The current literature on attitudes towards sexual offenders is largely descriptive in nature. That is, researchers have predominantly made use of one of the measures described previously (typically either the ATS or CATSO), and administered these scales among different groups in order to identify potential between-groups differences. This section is arranged in three parts. First, we describe demographic factors that have been found to impact upon the attitudes of different groups. Although we acknowledge that 'demographic factors' usually refers to a limited range of issues (e.g., age, gender, ethnicity, education, and socioeconomic status), previous work in this area of research has included issues such as sexual victimization and newspaper readership as a demographic issue. As such, when we refer to 'demographic factors', we refer to issues that are relevant to the identity of the person providing information about their attitudes, meaning that these wider issues (as well as personality factors) are captured under this heading. Second, we examine the role of offenseand offender-related factors in attitudes and perceptions of sexual offenders. Issues that are considered here are offender demographics, and attributions that we make about their levels of intent or culpability. Third, we examine the literature on professional influences on attitudes, and specifically set out a range of research findings that relate to the views of professionals working with sexual offenders.

\subsection{Demographic influences on attitudes towards sexual offenders}

Only two published studies (conducted in Australia/New Zealand) have sought to explicitly examine the general influence of demographic factors on attitudes and perceptions 
about sexual offenders (measured using the CATSO; Shackley et al., 2014; Willis, Malinen, \& Johnston, 2013). The only demographic factor that was found to be influential in moderating attitudes towards sexual offenders in both of these studies was educational attainment, with people holding higher-level qualifications expressing more positive (or, rather, less negative) attitudes than those with lower qualifications (see also Brown,1999, and Harper \& Hogue, 2015a, who support this finding within a British context).

These findings support the inconsistent nature of demographic differences in relation to attitudes toward sexual offenders. The majority of studies report no such demographic differences (Hogue \& Peebles, 1997; Kjelsberg \& Loos, 2008; Katz-Schiavone, Levenson, \& Ackerman, 2008). Some studies (conducted in a range of jurisdictions, including the U.K., Australia/New Zealand, and Norway) have indicated differences in attitudes based on gender (Ferguson \& Ireland, 2006; Higgins \& Ireland, 2009; Radley, 2011; Willis et al., 2013), and age (Brown, 1999; Craig, 2005; Kjelsberg \& Loos, 2008), although the direction of these differences are inconsistent between studies. In relation to parenthood, most studies find no differences between parents and non-parents in relation to global attitudes towards sexual offenders (e.g., Craun \& Theriot, 2009). However, findings reported by Levenson et al. (2007) found that, compared to non-parents, parents in the U.S. were more likely to express fear when asked about this group of offenders, and reject locally-based rehabilitation facilities ${ }^{1}$.

Numerous authors have theoretically linked newspaper readership with negative views about sexual offenders through the creation of homogeneous stereotypical images (e.g., Corabian \& Hogan, 2012; Galeste, Fradella, \& Fogel, 2012; Harper \& Hogue, 2015b; Harris \& Socia, 2014; McCartan, 2010, McCartan, Kemshall, \& Tabachnick, 2015; Quinn, Forsyth, \& Muller-Quinn, 2004; Thakker, 2012). In one of the only published studies to empirically

\footnotetext{
${ }^{1}$ While this is not necessarily an attitudinal outcome, this finding does suggest that the behavioural manifestations of attitudes may change as a function of some demographic factors
} 
examine this link, Harper and Hogue (2015a) found that British readers of tabloid publications (comprised of negativity and hostility about sexual offenders; Harper \& Hogue, 2015b) expressed much more negative perceptions about sexual offenders than readers of broadsheets, whose reputation is more balanced.

Olver and Barlow (2010) published the only study to examine attitudes and perceptions about sexual offenders specifically in relation to personality factors. Although few differences emerged in their analyses, the personality factor of 'openness to experience' (defined as having an active imagination and high levels of intellectual curiosity; McCrae \& John, 1992) was significantly associated with a more rehabilitative stance to sentencing sexual offenders. Although this personality factor has been theoretically and empirically linked to political liberalism (e.g., Roets, Cornelis, \& van Hiel, 2014), there were no significant differences in Olver and Barlow's (2010) study between American political 'Liberals' and 'Conservatives' in relation to their perceptions about sexual offender sentencing and risk.

Several studies have examined the role of sexual victimization, both direct (being a victim) and indirect (knowing a victim), on attitudes towards sexual offenders. The majority of these studies have found no attitudinal differences between people who did or did not know a victim of a sexual offense (Katz-Schiavone et al., 2008, Sahlstrom \& Jeglic, 2008; Willis et al., 2013). In the two studies that have found differences between these two groups (Ferguson \& Ireland, 2006; Nelson, Herlihy, \& Oescher, 2002), more positive attitudes were reported by participants who did know somebody who had been sexually victimized. This may be reflective of the typicality of sexual offending being perpetrated by somebody who is known by the victim (Radford et al., 2011). Consistent with this assertion, Sahlstrom and Jeglic (2008) reported that participants in their sample who did know an offender expressed 
more positive attitudes than those who did not know an offender (but see Willis et al., 2013), who found no significant attitudinal differences between these two groups).

\subsection{Offense-related influences on attitudes towards sexual offenders}

As King and Roberts (2015) argue, “when asked about 'sex offenders' many are inclined to envision the media-proliferated stereotypical image of a violent, predatory male pedophile" (p. 2). In line with empirical and theoretical ideas advanced by Salerno et al. (2010) and Harper and Hogue (2014), this could mean that judgments made about sexual offenders in general may be more punitive than those made about specific cases that do not necessarily match this prototypical image. Offender- and offense-specific information has been found to have a substantial impact on attitudes and perceptions about sexual offenders. Examples of such information includes the age of the offender (older perpetrators are judged more negatively; e.g., Harper, 2012; Sahlstrom \& Jeglic, 2008), and the gender of the offender (male perpetrators are judged more negatively than females; e.g., Gakhal \& Brown, 2011).

Information about the personality of sexual offenders have also been found to be influential in moderating attitudes towards these offenders. Cohn, Dupuis, and Brown (2009), for example, reported that students judged a male perpetrator of rape as being more responsible for the act when he was portrayed as having a bad reputation (operationalized as pursuing casual sex with multiple partners), as opposed to when he was portrayed as having a 'gentlemanly' reputation. A finding such as this further serves to highlight the importance of social stereotyping.

Hogue and Peebles (1997) found that criminal justice professionals provided more punitive sentencing recommendations when a rapist explicitly had an intention of having sex with a woman regardless of her (lack of) consent. However, there were no significant 
differences in sentencing recommendations in relation to the presence (or absence) of remorse after the rape had been committed. These results corroborated Kleinke, Wallis, and Stadler's (1992) findings from a student sample. Similarly, Burris and Rempel (2012) reported a significant softening of judgments about a rapist when he was unable to achieve an erection due to a lack of victim consent (indicative of a lack of rape intention). In contrast, no differences in attribute evaluations were found when the offender's sexual dysfunction was as a result of an attack of conscience (indicative of remorse for his behavior). These findings have potentially substantial implications within the courtroom, with a defendant's level of belief in the consent of a potential victim being of high importance for jurors when reaching their verdicts.

\subsection{Professional influences on attitudes towards sexual offenders}

The most commonly reported direct influence on attitudinal outcomes is experience of working with sexual offenders. In his original ATS paper, Hogue (1993) reported an incremental pattern of attitudinal differences between different groups of professionals. Police officers expressed the most punitive attitudes, followed in turn by prison officers not involved in offender treatment, prison officers involved in offender treatment, probation officers, and prison psychologists. Subsequent research has consistently supported the link between exposure to sexual offenders within a work environment (particularly treatmentbased work) and more positive attitudes towards sexual offenders (measured using the ATS; Blagden, Winder, \& Hames, 2014; Gakhal \& Brown, 2011; Hogue \& Peebles, 1997; Johnson, Hughes, \& Ireland, 2007; Radley, 2011). One interpretation of these results is that people who hold less negative attitudes towards sexual offenders are drawn to jobs that involve working in a therapeutic or supportive role with this population. However, it has been found that undergoing more than 30 hours of training to work therapeutically with sexual 
offenders improves attitudes, relative to less or no training (Simon \& Arnaut, 2011). Thus, it is more likely the case that working in a supportive or therapeutic manner with sexual offenders improves one's attitudes towards sexual offenders. The precise psychological processes responsible for this attitude change have not been robustly examined, although some authors have suggested that the dispelling of social myths and stereotypes about sexual offenders plays a key role (Sanghara \& Wilson, 2006).

Finally, teachers and students have been found to both hold more negative attitudes than probation workers and psychologists involved in sexual offender treatment and management (Kjelsberg \& Loos, 2008; Sanghara \& Wilson, 2006). Gakhal and Brown (2011) and Harper (2012), however, reported that students tend to express more positive attitudes towards sexual offenders than do members of the general public. This finding of community members expressing the most negative attitudes is also reported by Higgins and Ireland (2009), and Johnson et al. (2007). These findings are also consistent with the demographic data around educational attainment having a positive effect on attitudes towards sexual offenders (e.g., Brown, 1999; Harper \& Hogue, 2015a).

\subsection{Section summary and future directions}

A range of demographic and personality-related concepts have been found to be inconsistently related to both positive and negative stances. As such, no clear conclusions can be drawn about the influence of demographics on responses to sexual crime. The single factor that has consistently been found to potentially have a positive impact on attitudes is exposure to sexual offenders, either in a professional or personal capacity. Despite the apparent lack of demographic-based differences in attitudes towards sexual offenders, those that do exist provide researchers with a useful framework for discussing issues related to sexual crime in different areas. For example, the differences between tabloid and broadsheet newspaper 
readers may indicate that different approaches are required by academics communicating through these different media channels. This conclusion indicates that our current 'one-sizefits-all' approach to improving societal attitudes about sexual offenders may require some level of revision.

The process underlying this improvement in attitudes appears to be the breaking down of myths and stereotypes about sexual offenders, which may be informed through skewed and emotional media reports. Considering this, addressing societal stereotypes about sexual offenders, either directly through education, or indirectly through incidental exposure to counter-stereotypical exemplars, may be a potential route to positive attitude change.

Consistent with the theoretical assertions of both Salerno et al. (2010) and King and Roberts (2015), research that surveys attitudes towards sexual offenders in a general sense may be skewed by the activation of stereotypical images. Stereotypes are viewed as a type of category-based schema (Hilton \& von Hippel, 1996). As such, Harper and Bartels (in press) conceptualized the cognitive representation that people typically hold about sexual offenders as being a "sexual offender schema" (i.e., a knowledge structure that organizes information in a more abstract manner).

Category-schemas can influence people's judgments of a person, particularly when the person is judged to be typical of the category (Fiske, Neuberg, Beattie, \& Milburg, 1987). This judgment of fit with a category is consistent with Tversky and Kahneman's (1974) representativeness heuristic. In the present context, people may see the phrase 'sexual offender' and judge how representative the person is of the stereotypical image they hold in memory. Harris and Socia (2014) tentatively drew upon this framework in their analysis of how using the "sex offender" label (instead of the phrase "people who have committed crimes of a sexual nature" led to significantly more punitive responses. Similarly, the representative categories of 'monstrous offenders' and 'vulnerable victims' have also been 
found to moderate policy responses to sexual offenders (Pickett, Mancini, \& Mears, 2013). This approach could help to explain the negative reactions that people exhibit in response to media reports that propagate the stereotypical view of sexual offenders. As Armstrong and Nelson (2005) suggested, "readers of news stories may encounter individuals and events that match an existing stereotype, which may trigger heuristic processing of that story" (p. 822). The precise content of many people's "sexual offender schema" is not currently known. In establishing exactly what this schematic representation (i.e., stereotype) of a sexual offender is comprised of, it may be possible to further theorize about the role of representativeness in guiding attitudes and perceptions of sexual offenders. Thus, studies should seek to examine the content of such stereotypes.

It should also be noted, however, that the extent to which the sexual offender schema affects judgments may be dependent on whether people believe sexual offenders are fixed in their ways (consistent with an entity implicit theory of sexual offending) or are able to change (consistent with an incremental implicit theory). Harper and Bartels (in press) recently found that people holding incremental implicit theories about sexual offending hold less negative attitudes towards sexual offenders and advocate less punitive sentencing judgments, regardless of whether an offender matched the stereotypical view of a child abuser. Again, this demonstrates that, in order to develop a comprehensive understanding of people's attitudes to towards sexual offenders, it is crucial to further investigate the cognitive structures and processes underlying such attitudes.

\section{The malleability of attitudes and perceptions about sexual offenders}

The implicit aim of much of the research in this area has been to identify potential between-groups differences in attitudes towards sexual offenders, with an eventual aim being to formulate strategies for influencing these views. In this section, we review a number of 
intervention studies that have sought to specifically influence (i.e., improve) attitudes towards sexual offenders. This is an important endeavor in light of the conceptual work outlined in the introduction to this review, which highlights the potential importance of attitudes in relation to the effective treatment and reintegration of sexual offenders (e.g., Willis et al., 2010).

\subsection{Professional training programs}

Hogue (1994) measured attitudes towards sexual offenders both before and after a three week training program that was delivered to sexual offender treatment facilitators within the British prison system. This program was comprised of modules in relation to the theories of sexual offending, the goals of treatment, and the practical skills needed to work effectively with this client group (Hogue, 1991). At the end of the program, participants expressed significantly more positive attitudes towards sexual offenders (measured using the ATS) than at the beginning. A six-month follow-up survey found that participants felt significantly more confident and competent in their job role, and a majority suggested that their treatment groups were more successful as a result of the training program. However, ATS scores were not examined at this follow-up stage. Further, there was no control group used by Hogue (1994), making it difficult to directly attribute the improvements in attitude scores to the training program (as opposed to work-based exposure to sexual offenders).

Similarly, Craig (2005) examined the impact of an intensive two-day training program in a sample of probation workers involved with sexual offender treatment. This program was comprised of modules about theories of sexual offending, working constructively with sexual offenders, assessing risk, and challenging common myths. Consistent with Hogue's (1994) results, Craig (2005) reported an increase in participants' confidence in relation to working with sexual offenders. However, no changes in attitudes (as measured by the ATS) were found as a result of the training. Kjelsberg and Loos (2008) also failed to find any significant 
changes in ATS scores following a compulsory two-day training workshop delivered to staff working within the Norwegian prison service.

Harper (2012) surveyed undergraduates taking psychology and non-psychology courses in British universities. No significant differences were found in the ATS scores of psychology and non-psychology students, nor between subgroups of psychology students. Harper (2012) suggested that undergraduate education in forensic psychology may be insufficient at challenging societal-level stereotypes about sexual offenders.

The discrepancy between Hogue's (1994) findings and those reported by Craig (2005), Kjelsberg and Loos (2008), and Harper (2012) can be explained by data provided by Simon and Arnaut (2011). They found differences in ATS scores after different lengths of training programs. Although no specific training to change attitudes was examined, Simon and Arnaut (2011) found that licensed forensic professionals who had engaged in more than 30 hours of training in working with sexual offenders expressed significantly more positive attitudes towards sexual offenders than participants who had received less or no training. These results indicate the potential effectiveness of extended and intensive training programs, with a specific focus on working with sexual offenders, in improving attitudes among professionals.

\subsection{Social education programs}

Kleban and Jeglic (2012) investigated the utility of various psycho-educational methods for influencing attitudes towards sexual offenders. Methods that were evaluated in their study included 'reading' (i.e., participants read a short informative piece about sexual offenders), 'presentation' (i.e., participants read a short informative piece about sexual offenders, and then attended a presentation), and 'discussion' (i.e., participants read a short informative piece about sexual offenders, attended a presentation, and then discussed the presentation with others). Kleban and Jeglic (2012) reported that their interventions had been a success, 
suggesting that deeper consideration of the issue of sexual offending led to significant improvements in attitudes. However, Kleban and Jeglic (2012) interpreted high ATS scores as being indicative of negative attitudes. As stipulated by Hogue (1993), higher scores on the ATS reflect more positive attitudes (see Section 2.1). Thus, it was unclear as to whether the ATS data were scored according to established guidelines. If there was an interpretative error, then deeper consideration of sexual offenders actually led to significantly more negative attitudes in Kleban and Jeglic's (2012) study.

More recently, Malinen et al. (2014) examined the malleability of public attitudes towards sexual offenders using manipulations of mock news stories. They reported that participants presented with an 'informative' mock news story expressed significantly more positive attitudes (as measured by the CATSO) than participants in a control condition (no mock story presented). There was a non-significant difference in the attitudes between participants presented with the 'informative' or 'typical' (fear-laden) mock news story. Further, no significant group differences were reported in relation to implicit attitudes towards sexual offenders (that is, response times to 'positive' and 'negative' ST-IAT blocks were unchanged as a function of these experimental stimuli). Malinen et al. (2014) concluded that, while there is potential to influence public attitudes towards sexual offenders through media presentations, repeated exposure to information targeted at emotional responses to sexual crime may be needed to achieve reliable and long-lasting attitude change.

\subsection{The influence of labels on attitudes and perceptions about sexual offenders}

Not only do media reports potentially influence generalized attitudes towards sexual offenders (see Section 3.1), but they also have the ability to focus public attention on certain kinds of sexual crime, and the characteristics of those who perpetrate these types of offenses. 
Harper and Hogue (2015b) reported that lay observations about the differences in attitudes towards sexual offenders among newspaper readership groups may be due to the emotionally-laden descriptor attributed to the perpetrators of sexual crime in particular publication types. These descriptors are thus conceptualized as labels for stereotypical images held by readers, around which to based attitudes and judgments about sexual offenders. Examining this effect of the 'sexual offender' label more directly, Harris and Socia (2014) presented American participants with a series of policy positions. They reported that participants expressed more punitive responses to sexual crime (e.g., support for social network bans, registration procedures, and residency restrictions) when people were described as "sex offenders" than when they were described as "people who have committed crimes of a sexual nature”. Harris and Socia's (2014) findings are thus supportive of King and Roberts' (2015) assertion that there is something inherent in the 'sexual offender' label that leads to more visceral punitive responses.

Harper and Hogue (2014) found that a large proportion of British media reports about sexual crime focus on offenses perpetrated against children. Additionally, it has been reported that sexual offenders against children are homogeneously labeled as 'pedophiles' (Feelgood \& Hoyer, 2008; Harper \& Hogue, 2015b; Harrison, Manning, \& McCartan, 2010; Silverman \& Wilson, 2002). Recent research has shown that the impact of the 'pedophile' label on judgments (e.g., about sentencing) can be profound. For example, Imhoff (2015) recently found that people were judged to be more responsible for their urges when described using the 'pedophile' label, than when described as "people with a sexual interest in [prepubescent] children". Participants also advocated harsh punishments for those described as "pedophiles", even in the absence of an offense being committed.

Similarly, Jahnke, Imhoff, and Hoyer (2015) surveyed community members across two studies in Germany and the USA in order to examine levels of stigmatization towards 
'pedophiles'. They reported that a majority of participants associated the 'pedophile' label with the concepts of fear and danger. Pedophiles were also subject punitive judgments about social distance (i.e., befriending behavior) and criminal sentencing. In relation to punishment judgments, Jahnke et al. (2015) reported that approximately half of participants believed pedophiles should be incarcerated, and $14-27 \%$ advocated the view that they would be better dead, despite being explicitly informed that the person in question had never been convicted of a criminal offense.

\subsection{Section summary and future directions}

Building on the review of factors that underpin attitudes and perceptions (Section 3), the research literature around the malleability and manipulation of attitudes towards sexual offenders indicates that addressing stereotypes is an important practice. In the published work about influencing the attitudes of professionals working with sexual offenders, the length of training programs appears to be a key consideration (Simon \& Arnaut, 2011). This issue is mirrored within the work on changing social attitudes, with a number of studies having failed to bring about substantial attitudinal changes based upon single exposures to experimental stimuli (Kleban \& Jeglic, 2012; Malinen et al., 2014).

The activation of emotionally-charged stereotypes, particularly around the sexual abuse of children ('pedophilia', within the popular lexicon), emerges in the recent literature as an important process in guiding societal and personal responses to sexual crime (Harper \& Hogue, 2014; Imhoff, 2015; Jahnke et al., 2015). Within the context of Gawronski and Bodenhausen's (2006) Associative-Propositional Evaluation model and its relation to attitude change, the proliferation of such stereotypes within the mainstream media (Harper \& Hogue, 2015b; King \& Roberts, 2015) may contribute to the development of deeply-held implicit theories about who 'sexual offenders' typically are (Harper \& Bartels, in press). As suggested 
by Malinen et al. (2014), this may mean that a cultural shift in the ways in which sexual crime is discussed within the media may be needed in order to address these societally-held stereotypes.

Section 3.4 offered some suggestions for future research into the psychological factors underpinning attitudes towards sexual offenders. We argue that this theoretical work will be of great importance when researchers come to work on novel ways of influencing attitudes towards sexual offenders. However, these approaches can only be accurately formulated once studies have developed theoretical frameworks for examining these constructs.

\section{Why are attitudes and perceptions about sexual offenders important?}

As highlighted in the introduction to this review, attitudes towards sexual offenders have been implicated as influencing a number of areas related to the successful reintegration of sexual offenders into the community (Willis et al., 2010). However, there has been little attention paid to the role of attitudes within clinical contexts. Additionally, Willis et al.'s (2010) review came before recent theoretical developments into the sexual offending desistance process (Göbbels, Ward, \& Willis, 2012). As such, a more recent examination of the importance of studying attitudes in these contexts is warranted.

\subsection{Attitudes towards sexual offenders and clinical practice}

Within the clinical psychology literature, and emerging in the area of offender rehabilitation, the modality of treatment provision (i.e., cognitive-behavioral therapy vs. psychotherapy vs. person-centered approaches, etc.) is argued to be of less importance than the therapeutic alliance between clients and practitioners (Blow, Sprenkle, \& Davis, 2007; Duncan, Miller, \& Sparks, 2004; Ward \& Brown, 2004). With this in mind, it may be the case that treatment providers' attitudes and perceptions about sexual offenders have an 
important impact on their clinical work, particularly as a responsivity issue (e.g., the therapeutic relationship).

Blagden et al. (2014) used Dweck's (2000) 'entity' and 'incremental' implicit theory dichotomy to assess whether forensic professionals believed offending behavior to be fixed or changeable, respectively. Blagden et al. (2014) reported a positive association $(r=.50)$ between ATS scores and incremental implicit theories, indicating that positive attitudes towards sexual offenders were associated with the belief that offenders do have the potential to eventually desist from crime (see also Harper \& Bartels (in press) who replicated this finding).

Hogue (2015) reported findings from a recent study that examined the relationship between attitudes towards sexual offenders and risk judgments within a sample of licensed forensic professionals. A significant negative correlation $(r=-.32)$ was found between ATS21 scores and risk judgments. Similar correlation coefficients were also reported in relation to the 'Intent' and 'Social Distance' factors of the ATS-21 measure. Interpreting these relationships, higher perceptions of sexual offender risk is associated with the belief that sexual offending occurs due to high levels of offender intent. Also, an increased perception of risk is linked with to greater a desire to be socially distant from sexual offenders.

Beech and Hamilton-Giachritsis (2005) examined the therapeutic climate within 12 sexual offender treatment groups in the United Kingdom. They found that group members' belief that the group leader (therapist) was supportive encouraged the fostering of interpersonal communication. In turn, this communication within the group was associated with increased ratings of group cohesiveness, which was subsequently associated with treatment effectiveness (as measured through significant reductions in offense-supportive cognitions). These findings are suggestive of the view that the very nature of a supportive 
therapist undertaking work with sexual offenders can have an indirect positive effect on treatment outcomes, highlighting the importance of examining staff attitudes.

\subsection{Attitudes towards sexual offenders and social reintegration}

Willis et al. (2010) highlighted the need to understand and address community members' negative attitudes towards sexual offenders within the context of reintegration and desistance from crime. They argued that these negative attitudes form the basis of preferences for punitive public policies (an assertion supported by Harper \& Hogue's (2015a) PSO development data). Willis et al. (2010) drew upon criminological literature around desistance from crime (Carlsson, 2011; LeBel et al., 2008; Maruna, 2001; Sampson \& Laub, 2003) to suggest that societal negativity subsequently acts as a hindrance to successful community reintegration. This hindrance takes many forms, such as an inability for sexual offenders to obtain adequate accommodation, to access occupational training and/or employment, or to forge close personal relationships once they return to the community.

Drawing on similar literature, Göbbels et al. (2012) formulated the Integrated Theory of Desistance from Sexual Offending (ITDSO). This is a four-stage theory describing the processes by which sexual offenders transition from incarceration to living a crime-free life. Phase one is labeled 'decisive momentum' and refers to the stage at which a former sexual offender makes a conscious decision that their offending behavior is problematic and needs to stop, through processes of self-realization, or as a result of some external catalyst (e.g., a new relationship, or changes in life circumstances). In phase two ('rehabilitation'), the tenets of the Good Lives Model of offender rehabilitation (GLM; Ward \& Maruna, 2007), strengthsbased approaches (Ward \& Mann, 2004), and general desistance-strengthening principles are brought together in order to form a coherent view of sexual offender rehabilitation that focuses on the successful "reconstruction of the self" (Göbbels et al., 2012, p. 457). The focus 
here is on providing support for people who want to change their sexual offending behavior by helping them develop the skills needed to do so through positive identity restructuring. Phase three ('re-entry') highlights the importance of an external rehabilitation-reinforcing environment, within which people with convictions for sexual offenses can begin to rebuild and maintain their new identities as non-offenders. Finally, in phase four ('normalcy'), these individuals fully adopt this new identity, and view themselves as non-offenders.

The first two phases of the ITDSO focus on clinically-relevant issues, such as readiness to change (Prochaska \& di Clemente, 1982) and individualized rehabilitation plans. Phases three and four, however, adopt a more social perspective, and describe the desistancestrengthening (or desistance-impeding) influences of the external social environment. Göbbels et al. (2012) identified the importance of a rehabilitation-reinforcing social environment, such as the maintenance of positive social relationships and a strong nonoffender identity. However, they also point out the difficulties associated with achieving these social conditions with a history of sexual offending, through the processes of stigmatization, labeling, and strict probation restrictions (see also Jahnke \& Hoyer, 2013). As such, stigmatization can lead to the internalization of a sexual offender identity (the 'condemnation script'; Maruna, 2001). If the final two stages of the ITDSO are not successfully managed, then there is a risk that sexual offenders may struggle to accept and maintain the identity of a "non-offending member of society" (Farrell \& Calverley, 2006, p. 124), leading to an inflated risk for sexual recidivism. Thus, social conditions are an important theoretical component in the process of desisting from sexual offending.

Elaborating on the tenets of the ITDSO, it could be argued that the prevailing punitive consensus around sexual crime acts as a blockage to achieving what Ward and Stewart (2003) termed 'primary human goods' within the GLM. As a result, the development of what Göbbels et al. (2012) term a rehabilitation-reinforcing environment is impeded. Primary 
human goods form the basis of the GLM and are broadly defined as intrinsic life goals that, if pursued and acquired, lead to the "actualization of potentialities that are distinctively human" (Ward \& Gannon, 2006, p. 83).

From a cursory examination of the GLM's primary human goods (Purvis, 2010), it is clear that addressing the public's negative attitudes and reforming the ways in which sexual offenders are managed within the community after serving their criminal sentences are important topics to consider when promoting re-entry and normalcy. Lifelong registration procedures (and their associated restrictions), for example, limit the opportunities for former sexual offenders to achieve the goods of 'excellence in play', 'excellence in work', or 'excellence in agency', as they are not free to exercise autonomy in relation to where they live, socialize, or work. Achieving close ties (and thus the achievement of the primary goods of 'relatedness' and 'community') are also hampered through the effects of the lifelong 'sexual offender' label (Mingus \& Burchfield, 2012), as discussed in Section 4.3. Naturally, these experiences further limit the opportunities to achieve goods such as 'inner peace' and 'pleasure', and have been found in several studies to lead to feelings of hopelessness, selfstigma, and, in turn, an increased propensity for sexual re-offending (e.g., Jeglic, Calkins, \& Levenson, 2012; Levenson et al., 2007).

\subsection{Section summary}

The literature pertaining to the effect of attitudes on decision-making suggests that the endorsement of negative attitudes towards sexual offenders has profound implications for clinical and social judgments. Combining the results of Blagden et al. (2014) and Beech and Hamilton-Giachritsis (2005), professionals' attitudes towards sexual offenders may influence (and be reflected in) the therapeutic climate of treatment groups, which may have an impact on treatment outcomes. The relationships between attitudes and risk judgments reported by 
Hogue (2015) are perhaps more worrying from a human rights perspective, as these judgments have implications for sentencing and parole recommendations.

At the societal level, public attitudes towards sexual offenders may have profound effects at a number of levels. As highlighted in previous sections of this review, media outlets both inform and enhance public attitudes, leading to a self-fulfilling cycle of hostility and negativity. This cycle is related to several issues, including legislative discussions (Harper \& Hogue, 2014), support for punitive and restrictive policy positions (Koon-Magnin, 2015; Levenson et al., 2007), and the stigmatization of sexual offenders (Jahnke et al., 2015; Willis et al., 2010).

Research clearly shows that different professional groups hold varying attitudes towards sexual offenders (e.g., Hogue, 1993), and that these attitudes may impact on professional judgments and decision-making (e.g., Blagden et al., 2015; Hogue, 2015). While this is interesting, there has been virtually no explicit consideration of how differences in such attitudes may have an impact on criminal justice procedures and clinical practice. We argue that the holding of strong negative (or positive) attitudes towards sexual offenders may have a disproportionate impact on professional decision-making. This is critically important as differences in the personal attitudes of the professionals involved in these processes (e.g., judges, psychologists, nurses etc.) should not determine the outcome or management of individual cases.

Individual differences in attitudes towards sexual offenders may also have an impact in clinical settings. Strong negative attitudes are likely to impact on treatment efficacy and therapeutic alliance, through therapists' attitudes inhibiting the development of good therapeutic alliance which is critical for the implementation of effective treatment (e.g., Beech \& Hamilton-Giachritsis, 2005). At the same time, if attitudes are too positive then this may have an impact on the maintaining appropriate professional boundaries (Hamilton, 
2010), which has a critical impact on the security and safety of institutions and decisionmaking around risk. There is some evidence that extreme of attitudes towards sexual offenders impact negatively on the behavior of staff working with sexual offenders (Hogue \& Mann, 2000). Many organizations have put systems in place to support staff working with sexual offenders, with these professionals often experiencing high levels of stress and burnout (Kadambi \& Truscott, 2003; Shelby, Stoddart, \& Taylor, 2001). As such, preexisting attitudes might be an important consideration in staff selection processes.

Risk judgments about violence have been found to be strongly related to how the professional feels about the patient (e.g., Dernevik, Falkeim, Holmqvist, \& Sandell, 2001), and recent preliminary findings suggest that the attitudes of qualified forensic professionals has a significant impact on risk judgments of sexual offenders (Hogue, 2015). Further work is required to better understand the impact that attitudes may have on clinical decision-making. This might include research being conducted into sentencing and appeal decisions, selection and admission for treatment, judgments about clinical progress and treatment need, parole and release judgments, and the development and enactment of effective community resettlement plans (Willis \& Grace, 2009).

The overarching implication of attitudes towards sexual offenders in relation to clinical and social decision-making is that such attitudes can have a profound impact on the treatment and reintegration of people with sexual convictions, which aligns with the assumptions of the ITDSO (Göbbels et al., 2012). By not addressing such negativity effectively, there is a danger of impeding sexual offenders' reintegration prospects, and thus indirectly increasing their risk of recidivism. 


\section{Conclusions}

\subsection{Sexual crime as a public health issue}

Sexual crime has been identified as a "silent-violent epidemic" for more than two decades (American Medical Association, 1995), with major organizations advocating for interventions before a crime has been committed via primary and secondary prevention initiatives (e.g., Association for the Treatment of Sexual Abusers, 2011). Schemes that encourage men who are have (and are concerned about) inappropriate sexual thoughts about children to come forward for anonymous treatment and counseling, such as Project Prevention Dunkelfeld (Beier et al., 2009; Beier et al., 2016), have been found to be successful in preventing cases of sexual abuse (Beier et al., 2015).

At present, mainstream responses and interventions for sexual crime take place 'afterthe fact', and focus primarily on addressing the issues that contributed to the offender's commission of the crime, and the resultant trauma experienced by the victim. By adopting a more proactive approach that seeks to intervene before an offense has taken place, it may be possible to improve the life prospects of many people. Potential sexual offenders, for instance, would receive treatment before committing a crime, meaning that they can avoid being labeled and subjected to harsh restrictions on their liberty. Potential victims also benefit, as they can potentially avoid the trauma of being subjected to sexual abusive behavior.

Consistent with arguments advanced by the Association for the Treatment of Sexual Abusers (2011), the prevention of sexual crime should be considered a public health issue. Adopting such an approach requires a cultural change in how potential sexual offenders are viewed within modern societies. For example, potential sexual offenders who are struggling with their sexual urges must feel comfortable to come forward to seek help, and a shift in 
social attitudes will be key in achieving this level of confidence. It is this issue - influencing public attitudes such that people understand and are comfortable in the knowledge that potential 'sexual offenders' are able to live law-abiding lives - that should be the focus of researchers examining public attitudes towards sexual offenders.

\subsection{Developing research into attitudes towards sexual offenders}

This review has presented a comprehensive overview of the currently available literature in the area of attitudes towards sexual offenders. While this is an ever-developing area of academic inquiry, there are a number of pertinent factors that researchers in this area should consider when formulating and conducted research programs with the above focus in mind.

Throughout Section 2, we highlighted a range of standardized self-report measures that are used in this area. However, there have been some examples whereby standardized instructions for using these measures have not been correctly implemented. Studies such as Kleban and Jeglic (2012) highlight the importance of scoring and interpreting attitudinal measures correctly. This is an issue in several studies (e.g., Johnson et al., 2007; Radley, 2011; Sanghara \& Wilson, 2006). Having inconsistently-scored studies using the same measures within the same body of literature makes it particularly difficult to compare scores between the samples recruited by different researchers. For example, the mean ATS score attributed to members of the public by Johnson et al. (2007) was almost equivalent to the scores attributed to sexual offenders in Hogue's (1993) original development paper. Taking these scores at face value could lead to erroneous interpretations being drawn about particular groups' attitudes towards sexual offenders, or indeed about the societal view about sexual crime. These researchers score ATS items from 1-5 (not 0-4, as advised by Hogue, 1993), 
meaning that attitudes within their samples appeared to be substantially more positive than they would have if the measure was scored correctly.

The addition of the PSO measure (Harper \& Hogue, 2015a) to the literature offers an opportunity to develop and apply a conceptually clear and consistent experimental paradigm in this area of research. That is, the ATS-21 offers a comprehensive assessment of attitudes towards sexual offenders (consistent with the tripartite view of attitudes advanced by Breckler, 1984). After gathering these baseline attitudinal data, researchers can use experimental stimuli (e.g., offense vignettes), and administer the PSO as an outcome measure to examine the impact of such stimuli while controlling for baseline attitudinal orientations.

As highlighted in Section 2.4, there has been little use of indirect attitudinal assessment procedures, despite these having great potential to uncover attitudes that are less affected by external factors such as socially-desirable responding (Banse \& Imhoff, 2013). Moreover, there are some emerging methodological advances in the area of indirect assessment that may be beneficial to researchers, particularly those interested in examining real-time decisionmaking processes related to sexual crime. Most established indirect attitudinal measures use reaction times to assess the speed in which someone makes a decision (including Malinen et al. (2014), who are they only researchers to date to publish results using indirect measures in this area of research). However, new technologies (e.g., MouseTracker; Freeman \& Ambady, 2010) allow researchers to examine the competition between two competing response options (e.g., 'positive' and 'negative') in real-time. By using this type of paradigm, it may be possible to detect differences in the levels of ambivalence between two response options in spite of no differences in crude response times (as reported by Malinen et al., 2014). As such, we argue that scholars in this area should adopt these developing technologies in future research projects. 
Away from methodological considerations, we argue that an increased research focus is required in order to elucidate the potential implications of particular attitudinal orientations on social and clinical decision-making processes with regards to the sentencing, treatment, and post-conviction management of sexual offenders. This area of research is currently atheoretical. That is, there are a number of studies that have examined between-groups differences in ATS/CATSO scores, but very little work has been conducted in order to understand these differences from the perspective of underlying psychological processes. In the summary of Section 3 of this review, we offered a range of suggestions for developing research into the underlying psychological mechanisms that may lead to the development and expression of certain attitudinal orientations in relation to sexual offenders. Some research has already begun in this regard, with Harper \& Bartels (in press) examining the role of entity-based implicit theories in punitive attitudes and responses to sexual offenders. There has also recently been a number of studies looking at the effects of labels in driving decisionmaking in this area (Harris \& Socia, 2014; Imhoff, 2015).

These studies all appear to converge around the idea that examining attitudes towards sexual offenders using a dual-process approach may be an appropriate theoretical orientation to adopt. The issues highlighted through Sections 2 and 3 of this review indicate that the breaking down of stereotypes and the dispelling of myths about sexual offenders should be among the top priorities for researchers in this area. These constructs are conceptually similar to how Tversky and Kahneman (1974) framed their work on the 'representativeness heuristic'. That is, it can hypothesized that the extent to which a person holds a fixed idea about who a typical 'sexual offender' is will guide their judgments about this group (in a general sense), as well as views about specific cases of sexual crime. This is the underlying premise behind the promising results reported in Harper and Bartels' (in press) study into implicit theories, and is certainly an issue that requires further attention. Further, the affect 
heuristic is also implicated in moderating attitudes towards sexual offenders, with a number of studies arguing that we are led primarily by our automatic emotional reactions to contentious issues (e.g., Haidt, 2001; Slovic \& Peters, 2006). This is one potentially fruitful theoretical framework for attitude researchers to adopt in this area.

\subsection{Concluding remarks}

Attitudes towards sexual offenders play an important role in the development of social practices around the treatment and management of sexual offenders, as well as having substantial implications within clinical contexts. The existing literature in this area suggests that attitudes and perceptions about sexual offenders may be, at least in part, driven by media-proliferated and socially-constructed stereotypes about the types of people that sexual offenders are. This assertion is supported by studies reporting more punitive views being expressed by participants when asked to make judgments about sexual offenders (in a general sense) than in relation to specific counter-stereotypical cases (King \& Roberts, 2015; Salerno et al., 2010), as well as improved attitudes among participants with practical working experience with sexual offenders, or those endorsing fewer stereotypes (Gakhal \& Brown, 2011; Hogue, 1993; Sanghara \& Wilson, 2006).

It is proposed that the most fruitful way to improve attitudes towards sexual offenders is to examine the context of people's stereotypical images of sexual offenders, and to challenge these through the presentation of humanized exemplars. By doing this, sexual offenders can be presented in such a way as to be seen as people, rather than a monstrous 'other'. The goal of this research area should be to facilitate the development of a social environment within which reactionary punitive responses are replaced by empirically-based discussions about reducing sexual victimization through the prevention of sexual (re)offending. 


\section{References}

American Medical Association. (1995). Press release: The epidemic of sexual assault.

Chicago, IL: AMA.

Anonymous (in prep) - information masked for double-blind review

Armstrong, C. L., \& Nelson, M. R. (2005). How newspaper sources trigger gender stereotypes. Journalism and Mass Communication Quarterly, 82, 820-837. doi: $\underline{10.1177 / 107769900508200405 .}$

Association for the Treatment of Sexual Abusers (2011). Sexual abuse as a public health problem. Beaverton, OR: ATSA.

Banse, R., \& Imhoff, R. (2013). Implicit cognition and relationship processes. In J. Simpson \& L. Campbell (Eds.), The Oxford handbook of close relationships (pp. 475-499). Oxford, UK: Oxford University Press.

Beech, A. R., \& Hamilton-Giachritsis, C. E. (2005). Relationship between therapeutic climate and treatment outcome in group-based sexual offender treatment programmes. Sexual Abuse: A Journal of Research and Treatment, 17, 127-140. doi: 10.1007/s11194-0054600-3.

Beier, K. M., Ahlers, C. J., Göcker, D., Neutze, J., Mundt, I. A., Hupp, E., \& Shäfer, G. A. (2009). Can pedophiles be reached for primary prevention of child sexual abuse? First results of the Berlin Prevention Project Dunkelfeld (PPD). The Journal of Forensic Psychiatry \& Psychology, 20, 851 - 867. doi: 10.1080/14789940903174188.

Beier, K. M., Grundmann, D., Kuhle L. F., Scherner, G., Konrad, A., \& Amelung, T. (2015). The German Dunkelfeld project: A pilot study to prevent child sexual abuse and the use of child abusive images. Journal of Sexual Medicine, 12, 529-542. doi: 10.1111/jsm.12785.

Beier, K. M., Özdemir, U. C., Schlinzig, E., Groll, A., Hupp, E., \& Hellenschmidt, T. (2016). "Just dreaming about them"": The Berlin project for primary prevention of child sexual 
abuse by juveniles (PPJ). Child Abuse \& Neglect, 52, 1-10. doi:

10.1016/j.chiabu.2015.12.009.

Blagden, N., Winder, B., \& Hames, C. (2014). "They treat us like human beings" Experiencing a therapeutic sex offenders prison impact on prisoners and staff and implications for treatment. International Journal of Offender Therapy and Comparative Criminology. Advance online publication. doi: 10.1177/0306624X14553227.

Blow, A. J., Sprenkle, D. H., \& Davis, S. D. (2007). Is who delivers the treatment more important than the treatment itself? Journal of Marital and Family Therapy, 33, 298-317. doi: 10.1111/j.1752-0606.2007.00029.x.

Breckler, S., J. (1984). Empirical validation of affect, behavior, and cognition as distinct components of attitude. Journal of Personality and Social Psychology, 47, 1191-1205. doi: 10.1037/0022-3514.47.6.1191.

Brown, S. (1999). Public attitudes toward the treatment of sex offenders. Legal and Criminological Psychology, 4, 239-252. doi: 10.1348/135532599167879.

Brown, S. (2009). Attitudes towards sexual offenders and their rehabilitation: A special case? In J. Wood \& T. Gannon (Eds.), Public opinion in criminal justice (pp. 187-213). Cullompton, UK: Willan Publishing.

Burris, C. T., \& Rempel, J. K. (2012). Something in the way he moves? Interpersonal judgments of acquaintance rapists. Personal Relationships, 19, 89-102. doi: 10.1111/j.1475-6811.2010.01341.x.

Carlsson, C. (2011). Using 'turning points' to understand processes of change in offending: Notes from a Swedish study on life courses and crime. British Journal of Criminology, 52, 1-16. doi: 10.1093/bjc/azr062.

Church, W. T., Wakeman, E. E., Miller, S. L., Clements, C. B., \& Sun, F. (2008). The community attitudes toward sex offenders scale: The development of a psychometric 
assessment instrument. Research on Social Work Practice, 18, 251-259. doi:

$10.1177 / 1049731507310193$.

Cohn, E. S., Dupuis, E. C., \& Brown, T. B. (2009). In the eye of the beholder: Do behavior and character affect victim and perpetrator responsibility for acquaintance rape? Journal of Applied Social Psychology, 39, 1513-1535. doi: 10.1111/j.1559-1816.2009.00493.x.

Corabian, G., \& Hogan, N. (2012). Collateral effects of the media on sex offender reintegration: Perceptions of sex offenders, professionals, and the lay public. Sexual Offender Treatment, 12. Retrieved from http://www.sexual-offendertreatment.org/110.html.

Conley, T., Hill, K., Church, W. T., Stoeckel, E., \& Allen, H. (2011). Assessing probation and community corrections workers' attitudes toward sex offenders using the attitudes toward sex offenders (CATSO) scale in a rural State. Sexual Addiction \& Compulsivity, 18, 75-85. doi: 10.1080/10720162.2011.582775.

Craig, L. A. (2005). The impact of training on attitudes towards sex offenders. Journal of Sexual Aggression, 11, 197-207. doi: 10.1080/13552600500172103.

Craun, S.W., \& Theriot, M.T. (2009). Misperceptions of sex offender perpetration: Considering the impact of sex offender registration. Journal of Interpersonal Violence, 24, 2057-2072. doi: 10.1177/0886260508327706.

Dernevik, M., Falkeim, M., Holmqvist, R., \& Sandell, R. (2001). Implementing risk assessment procedures in a forensic psychiatric setting. In D. P. Farrington, C. Hollin, \& M. McMurran (Eds), Sex and violence: The psychology of crime and risk assessment (pp. 83-102). London, UK: Routledge.

Duncan, B. L., Miller, S. D., \& Sparks, J. A. (2004). The heroic client: A revolutionary way to improve effectiveness through client-directed, outcome-informed therapy. San Francisco, CA: Jossey-Bass. 
Dweck, C. S. (2000). Self-theories: their role in motivation, personality, and development. Hove, UK: Psychology Press.

Eagly, A. H., \& Chaiken, S. (1993). The psychology of attitudes. Orlando, FL: Harcourt Brace.

Farrall, S., \& Calverley, A. (2006). Understanding desistance from crime: Theoretical directions in resettlement and rehabilitation. New York, NY: Open University Press.

Feelgood, S., \& Hoyer, J. (2008). Child molester or paedophile? Sociolegal versus psychopathological classification of sexual offenders against children. Journal of Sexual Aggression, 14, 33-43. doi: 10.1080/13552600802133860.

Ferguson, K., \& Ireland, C. (2006). Attitudes towards sex offenders and the influence of offense type: A comparison of staff working in a forensic setting and students. The British Journal of Forensic Practice, 8, 10-19. doi: 10.1108/14636646200600009.

Fiske, S. T., Neuberg, S. L., Beattie, A. E., \& Milberg, S. J. (1987). Category-based and attribute-based reactions to others: Some informational conditions of stereotyping and individuating processes. Journal of Experimental Social Psychology, 23, 399-427. doi: 10.1016/0022-1031(87)90038-2.

Freeman, J. B., \& Ambady, N. (2010). MouseTracker: Software for studying real-time mental processing using a computer mouse-tracking method. Behavior Research Methods, 42, 226-241. doi: 10.3758/BRM.42.1.226.

Gakhal, B. K., \& Brown, S. J. (2011). A comparison of the general public's, forensic professionals' and students' attitudes towards female sex offenders. Journal of Sexual Aggression, 17, 105-116. doi: 10.1080/13552600.2010.540678.

Galeste, M., Fradella, H., \& Vogel, B. (2012). Sex offender myths in print media: Separating fact from fiction in U.S. newspapers. Western Criminology Review, 13, 4-24. 
Gawronski, B., \& Bodenhausen, G. V. (2006). Associative and propositional processes in evaluation: An integrative review of implicit and explicit attitude change. Psychological Bulletin, 132, 692-731. doi: 10.1037/0033-2909.132.5.692.

Gawronski, B., \& De Houwer, J. (2014). Implicit measures in social and personality psychology. In H. T. Reiss \& C. M. Judd (Eds.), Handbook of research methods in social and personality psychology (pp. 283-310). New York, NY: Cambridge University Press.

Göbbels, S., Ward, T., \& Willis, G. W. (2012). An integrative theory of desistance from sex offending. Aggression and Violent Behavior, 17, 453-462. doi: 10.1016/j.avb.2012.06.003.

Greenwald, A. G., McGhee, D. E., \& Schwarz, J. L. (1998). Measuring individual differences in implicit cognition: The implicit association test. Journal of Personality and Social Psychology, 74, 1464-1480. doi: 10.1037/0022-3514.74.6.1464.

Haidt, J. (2001). The emotional dog and its rational tail: A social intuitionist approach to moral judgment. Psychological Review, 108, 814-834. doi: 10.1037/0033295X.108.4.814.

Hamilton, L. (2010). The boundary seesaw model: good fences make for good neighbours. In A. Tennant \& K. Howells (Eds.), Using time, not doing time: practitioner perspectives on personality disorder and risk (pp. 181-194). Chichester, UK: Wiley.

Harper, C. A. (2012). In pursuit of the beast: Undergraduate attitudes towards sex offenders and implications for society, rehabilitation, and British psychology education. Internet Journal of Criminology. Retrieved from http://www.internetjournalofcriminology.com/Harper_In_Pursuit_of_the_Beast_IJC_July 2012.pdf.

Harper, C. A., \& Bartels, R. M. (in press). Implicit theories and offender representativeness in judgments of sexual crime. Sexual Abuse: A Journal of Research and Treatment. 
Harper, C. A., \& Hogue, T. E. (2014). A prototype-willingness model of sexual crime discourse in England and Wales. The Howard Journal of Criminal Justice, 53, 511-524. doi: 10.1111/hojo.12095.

Harper, C. A., \& Hogue, T. E. (2015a). Measuring public perceptions of sex offenders: Reimagining the Community Attitudes Toward Sex Offenders scale (CATSO). Psychology, Crime \& Law, 21, 452-470. doi: 10.1080/1068316X.2014.989170.

Harper, C. A., \& Hogue, T. E. (2015b). The emotional representation of sexual crime in the national British press. Journal of Language and Social Psychology, 34, 3-24. doi: 10.1177/0261927X14544474.

Harris, A. J., \& Socia, K. M. (2014). What's in a name? Evaluating the effects of the "sex offender" label on public beliefs and opinions. Sexual Abuse: A Journal of Research and Treatment. Advance online publication. doi: 10.1177/1079063214564391.

Harrison, K., Manning, R., \& McCartan, K. (2010). Multi-disciplinary definitions and understandings of 'paedophilia'. Social and Legal Studies, 19, 481-496. doi: $10.1177 / 0964663910369054$.

Higgins, C., \& Ireland, C. A. (2009). Attitudes towards male and female sex offenders: a comparison of forensic staff, prison officers and the general public in Northern Ireland. British Journal of Forensic Practice, 11, 14-19. doi: 10.1108/14636646200900004.

Hilton, J. L., \& von Hippel, W. (1996). Stereotypes. Annual Review of Psychology, 47, 237271. doi: 10.1146/annurev.psych.47.1.237.

Hogue, T. E. (1991). Sex offender treatment programme: Programme for core programme facilitators - 1991. London, UK: HM Prison Service.

Hogue, T. E. (1993). Attitudes towards prisoners and sex offenders. In N. C. Clark \& G. Stephenson (Eds.), DCLP occasional papers: sexual offenders. Leicester, UK: British Psychological Society. 
Hogue, T. E. (1994). Training multi-disciplinary teams to work with sex offenders: Effects on staff attitudes. Psychology, Crime \& Law, 1, 227-235. doi: 10.1080/10683169508411958.

Hogue, T. E. (2015, July). Attitudes to sex offenders. Paper presented at the BPS Division of Forensic Psychology Annual Conference. Manchester Metropolitan University, Manchester, UK.

Hogue, T. E., \& Mann, R. (2000, November). Working with sex offenders: Can we predict who makes a good therapist? Workshop presented at the Association for the Treatment of Sexual Abusers Annual Conference. San Diego, CA.

Hogue, T. E., \& Peebles, J. (1997). The influence of remorse, intent and attitudes toward sex offenders on judgments of a rapist. Psychology, Crime \& Law, 3, 249-259. doi: 10.1080/10683169708410821.

Imhoff, R. (2015). Punitive attitudes against pedophiles or persons with sexual interest in children: Does the label matter? Archives of Sexual Behavior, 44, 35-44. doi: 10.1007/s10508-014-0439-3.

Jahnke, S. \& Hoyer, J. (2013). Stigmatization of people with pedophilia: A blind spot in stigma research. International Journal of Sexual Health, 25, 169-184. doi: $10.1080 / 19317611.2013 .795921$.

Jahnke, S., Imhoff, R., \& Hoyer, J. (2015). Stigmatization of people with pedophilia: Two comparative surveys. Archives of Sexual Behavior, 44, 21-34. doi: 10.1007/s10508-0140312-4.

Jeglic, E. L., Calkins, C., \& Levenson, J. S. (2012). The prevalence and correlates of depression and hopelessness among sex offenders subject to community notification and residence restriction legislation. American Journal of Criminal Justice, 37, 46-59. doi: 10.1007/s12103-010-9096-9. 
Johnson, H., Hughes, J. G. \& Ireland, J. L. (2007). Attitudes towards sex offenders and the role of empathy, local of control and training: A comparison between a probationer police and general public sample. The Police Journal, 80, 28-54. doi:

10.1350/pojo.2007.80.1.28.

Jones, E. C. (2013). An examination of counseling professional/paraprofessionals attitudes toward adolescent sex offenders. SAGE Open, 2, 1-14. doi: 10.1177/2158244013501330.

Jussim, L. (2012). Social perception and social reality: Why accuracy dominates bias and self-fulfilling prophecy. New York, NY: Oxford University Press.

Kadambi, M. A., \& Truscott, D. (2003). Vicarious traumatization and burnout among therapists working with sex offenders. Traumatology, 9, 216-230. doi: $10.1177 / 153476560300900404$.

Katz-Schiavone, S., Levenson, J. S., \& Ackerman, A. (2008). Myths and facts about sexual violence: Public perceptions and implications for prevention. Journal of Criminal Justice and Popular Culture, 15, 291-311.

Kernsmith, P. D., Craun, S. W., \& Foster, J. (2009). Public attitudes toward sexual offenders and sex offender registration. Journal of Child Sexual Abuse, 18, 290-301. doi: $10.1080 / 10538710902901663$.

Kidd, D. C., Castano, E. (2013). Reading literary fiction improves theory of mind. Science, 342, 377-380. doi: 10.1126/science.1239918

King, L. L., \& Roberts, J. J. (2015). The complexity of public attitudes toward sex crimes. Victims \& Offenders. Advance online publication. doi: 10.1080/15564886.2015.1005266.

Kitzinger, J. (2008). 'Paedophile-in-the-community' protests: Press reporting and public responses. In G. Letherby, K. Williams, P. Birch, \& M. E. Cain (Eds.), Sex as crime? (pp. 356-376). Cullompton, UK: Willan Publishing. 
Kjelsberg, E., \& Loos, L. H. (2008). Conciliation or condemnation? Prison employees' and young people's attitudes towards sexual offenders. International Journal of Forensic Mental Health, 7, 95-103. doi: 10.1080/14999013.2008.9914406.

Kleban, H., \& Jeglic, E. (2012). Dispelling the myths: Can psychoeducation change public attitudes towards sex offenders? Journal of Sexual Aggression, 18, 179-193. doi: $\underline{10.1080 / 13552600.2011 .552795 .}$

Kleinke, C. L., Wallis, R., \& Stadler, K. (1992). Evaluation of a rapist as a function of expressed intent and remorse. The Journal of Social Psychology, 132, 525-537. doi: 10.1080/00224545.1992.9924732.

Koon-Magnin, S. (2015). Perceptions of and support for sex offender policies: Testing, Levenson, Brannon, Fortney, and Baker's findings. Journal of Criminal Justice, 43, 80880. doi: 10.1016/j.jcrimjus.2014.12.007.

LeBel, T. P., Burnett, R., Maruna, S., \& Bushway, S. (2008). The 'chicken and egg' of subjective social factors and desistance from crime. European Journal of Criminology, 5, 131-153. doi: 10.1177/1477370807087640.

Levenson, J. S., Brannon, Y. N., Fortney, T., \& Baker, J. (2007). Public perceptions about sex offenders and public protection policies. Analyses of Social Issues and Public Policy, 7, 1-25. doi: 10.1111/j.1530-2415.2007.00119.x.

Malinen, S., Willis, G. W., \& Johnston, L. (2014). Might informative media reporting of $\underline{\text { sexual offending influence community members' attitudes towards sex offenders? }}$

Psychology, Crime \& Law, 20, 535-552. doi: 10.1080/1068316X.2013.793770.

Maruna, S. (2001). Making good: How ex-convicts reform and rebuild their lives.

Washington, DC: American Psychological Association.

McCartan, K. F. (2010). Student/trainee-professional implicit theories of paedophilia. Psychology, Crime \& Law, 16, 265-288. doi: 10.1080/10683160802614144. 
McCartan, K. F., Kemshall, H., \& Tabachnick, J. (2015). The construction of community understandings of sexual violence: Rethinking public, practitioner and policy discourses. Journal of Sexual Aggression, 21, 100-116. doi: 10.1080/13552600.2014.945976.

McCrae, R. R., \& John, O. P. (1992). An introduction to the five-factor model and its applications. Journal of Personality, 60, 175-215. doi: 10.1111/j.14676494.1992.tb00970.x.

Melvin, K. B., Gramling, L. K., \& Gardner, W. M. (1985). A scale to measure attitudes towards prisoners. Criminal Justice and Behavior, 12, 241-252. doi: 10.1177/0093854885012002006.

Mingus, W., \& Burchfield, K. B. (2012). From prison to integration: Applying modified labeling theory to sex offenders. Criminal Justice Studies, 25, 97-109. doi: 10.1080/1478601X.2012.657906.

Nelson, M., Herlihy, B., \& Oescher, J. (2002). A survey of counsellor attitudes towards sex offenders. Journal of Mental Health Counseling, 24, 51-67.

Olver, M., E., \& Barlow, A. A. (2010). Public attitudes toward sex offenders and their relationship to personality traits and demographic characteristics. Behavioral Sciences and the Law, 28, 832-849. doi: 10.1002/bsl.959.

Pickett, J. T., Mancini, C., \& Mears, D. P. (2013). Vulnerable victims, monstrous offenders, and unmanageable risk: Explaining public opinion on the social control of sex crime. Criminology, 51, 729-759. doi: 10.1111/1745-9125.12018.

Prochaska, J. O., \& di Clemente, C. C. (1982). Transtheoretical therapy: Toward a more integrative model of change. Psychotherapy: Theory, Research, and Practice, 19, 276288. doi: $10.1037 / \mathrm{h} 0088437$. 
Proeve, M. J., \& Howells, K. (2006). Effects of remorse and shame and criminal justice experience on judgements about a sex offender. Psychology, Crime \& Law, 12, 145-161. doi: $10.1080 / 10683160512331316271$.

Purvis, M. (2010). Seeking a good life: Human goods and sexual offending. Germany: Lambert Academic Press.

Quinn, J. F., Forsyth, C. J., \& Muller-Quinn, C. J. (2004). Societal reaction to sex offenders: A review of the origins and results of the myths surrounding their crimes and treatment amenability. Deviant Behavior, 25, 215-232. doi: 10.1080/01639620490431147.

Radley, L. (2011). Attitudes toward sex offenders. Forensic Update, 66, 5-9.

Roets, A., Cornelis, I., \& van Hiel, A. (2014). Openness as a predictor of political orientation and conventional and unconventional political activism in Western and Eastern Europe. Journal of Personality Assessment, 96, 53-63. doi: 10.1080/00223891.2013.809354.

Sahlstrom, K. J., \& Jeglic, E. L. (2008). Factors affecting attitudes toward juvenile sex offenders. Journal of Child Sexual Abuse, 17, 180-196. doi: 10.1080/10538710801916705.

Salerno, J. M., Najdowski, C. J., Stevenson, M. C., Wiley, T. R., Bottoms, B. L., Vaca, R., \& Pimentel, P. S. (2010). Psychological mechanisms underlying support for juvenile sex offender registry laws: Prototypes, moral outrage, and perceived threat. Behavioral Sciences \& the Law, 28, 58-83. doi: 10.1002/bsl.921.

Sampson, R. J., \& Laub, J. H. (2003). Desistance from crime over the life course. In J. T. Mortimer \& M. Shanahan (Eds.), Handbook of the life course (pp.295-310). New York, NY: Kluwer Academic/Plenum.

Sanghara, K. K., \& Wilson, J. C. (2006). Stereotypes and attitudes about child sexual abusers: A comparison of experienced and inexperienced professionals in sex offender treatment. Legal and Criminological Psychology, 11, 229-244. doi: 10.1348/135532505X68818. 
Shackley, M., Weiner, C., Day, A., \& Willis, G. W. (2014). Assessment of public attitudes towards sex offenders in an Australian population. Psychology, Crime \& Law, 20, 553572. doi: 10.1080/1068316X.2013.793772.

Shelby, R. A., Stoddart, R. M., \& Taylor, K. L. (2001). Factors contributing to levels of burnout among sex offender treatment providers. Journal of Interpersonal Violence, 16, 1205-1217. doi: 10.1177/088626001016011006.

Shelton, L., Stone, J., \& Winder, B. (2013). Evaluating the factor structure and reliability of the community attitudes toward sex offenders (CATSO) scale. Journal of Criminal Psychology, 3, 115-126. doi: 10.1108/JCP-10-2012-0014.

Silverman, J., \& Wilson, D. (2002). Innocence betrayed: Paedophilia, the media and society. Cambridge, UK: Polity Press.

Simon, S., \& Arnaut, G. (2011, March). Psychologists' attitudes toward sex offenders. Poster presented at the International Congress of Psychology and Law. Hyatt Regency, Miami, FL.

Slovic, P., \& Peters, E. (2006). Risk perception and affect. Current Directions in Psychological Science, 15, 322-325. doi: 10.1111/j.1467-8721.2006.00461.x.

Tewkesbury, R., \& Mustaine, E. E. (2013). Law-enforcement officials' views of sex offender registration and community notification. International Journal of Police Science \& Management, 15, 95-113. doi: 10.1350/ijps.2013.15.2.305.

Thakker, J. (2012). Public attitudes toward sex offenders in New Zealand. Journal of Sexual Aggression, 18, 149-163. doi: 10.1080/13552600.2010.526245.

Tversky, A., \& Kahneman, D. (1974). Judgment under uncertainty: Heuristics and biases. Science, 185, 1124-1131. doi: 10.1126/science.185.4157.1124.

Visser, P. S., \& Cooper, J. (2003). Attitude change. In M. A. Hogg \& J. Cooper (Eds.), The Sage handbook of social psychology (pp. 211-231). Thousand Oaks, CA: Sage. 
Ward, T., \& Brown, M. (2004). The good lives model and conceptual issues in offender rehabilitation. Psychology, Crime \& Law, 10, 243-257. doi:

10.1080/10683160410001662744.

Ward, T., \& Gannon, T. A. (2006). Rehabilitation, etiology, and self-regulation: The comprehensive good loves model of treatment for sexual offenders. Aggression and Violent Behavior, 11, 77-94. doi: 10.1016/j.avb.2005.06.001.

Ward, T., \& Mann, R. (2004). Good lives and the rehabilitation of offenders: A positive approach to treatment. In A. Linley, \& S. Joseph (Eds.), Positive psychology in practice (pp. 598-616). Hoboken, NJ: Wiley.

Ward, T., \& Maruna, S. (2007). Rehabilitation: Beyond the risk paradigm. London, UK: Routledge.

Ward, T., \& Stewart, C. A. (2003). The treatment of sex offenders: Risk management and good lives. Professional Psychology, Research and Practice, 34, 353-360. doi: 10.1037/0735-7028.34.4.353.

Wigboldus, D. H. J., Holland, R. W., \& van Knippenberg, A. (2006). Single target implicit associations. Unpublished manuscript.

Willis, G. M., \& Grace, R. C. (2009). Assessment of community reintegration planning for sex offenders: Poor planning predicts recidivism. Criminal Justice and Behavior, 36, 494 512. doi: $10.1177 / 0093854809332874$.

Willis, G. M., Levenson, J. S., \& Ward, T. (2010). Desistance and attitudes towards sex offenders: Facilitation or hindrance? Journal of Family Violence, 25, 545-556. doi: 10.1007/s10896-010-9314-8.

Willis, G. M., Malinen, S., \& Johnston, L. (2013). Demographic differences in public attitudes towards sex offenders. Psychiatry, Psychology and Law, 20, 230-247. doi: $\underline{10.1080 / 13218719.2012 .658206 .}$ 
Wnuk, D., Chapman, J. E., \& Jeglic, E. L. (2006). Development and refinement of a measure of attitudes toward sex offender treatment. Journal of Offender Rehabilitation, 43, 35-47. doi: 10.1300/J076v43n03_03. 


\section{Highlights}

- There is inconsistency in the measurement of attitudes towards sexual offenders

- Exposure to sexual offenders is the best-supported factor for influencing attitudes

- Attitudes towards sexual offenders are malleable in the short-term, though evidence for long-term effects are lacking

- Attitudes towards sexual offenders are important in clinical and societal contexts

- The prevention of sexual crime should be considered a public health issue 